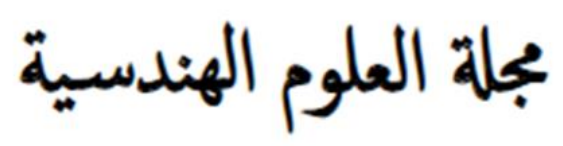

FES Journal of Engineering Sciences

\title{
Vertical Curve Computations Using a Developed Calculator
}

\author{
Adil I. Hassabo \\ Department of Civil Engineering, Alzaiem Alazhari University, Khartoum, Sudan \\ Corresponding author: E-mail: hassabo4@hotmail.com \\ Article history: Received 26 March 2019, Received in revised form 23 May. 2020, Accepted 23 May 2020
}

\begin{abstract}
In this paper an electronic calculator for vertical curve computations is developed in Microsoft Windows. The developed calculator used is successfully for vertical curve computations, and require entering of the curve length, tangent grades, setting out interval, and the elevation of the intersection points. Computations of vertical curves by the developed calculator are faster, easier, accurate, and less subject to errors comparable to the traditional method of calculations. Finally, the results obtained by the traditional and developed methods are presented for checking the behavior of the developed calculator.
\end{abstract}

Keywords: Developed Calculator, Computations, Vertical Curve, Parabolic Curve

\section{INTRODUCTION}

Vertical curves are arcs of circles, or parabolas, parabolas are ideal because they provide a constant rate of change of grade, and almost applied for vertical alignments. They are used to provide a gradual change in grade, and smooth transitions between tangents of grade lines in vertical planes for highways and railroads. There are two basic types of vertical curves crest and sag. In a crest curve the change in grade is negative; that is the curve turns downwards, while in a sag curve the change in grade is positive; and the curve turns upward.

When designing grade lines for highway and railroad projects several factors must be taken into account, these factors include: good fitting with existing ground profile so as to minimize the depths of cuts and fills, balancing the volume of materials of cut and fill, providing adequate drainage, and meeting some specification such as maximum specified grades, or meeting fixed elevations [1, 2].
After designing grade lines series of intersection points are produced, each defined by its station and elevation. A vertical curve is then chosen to join each pair of intersecting tangents. The elements of vertical curve is shown by figure (1)

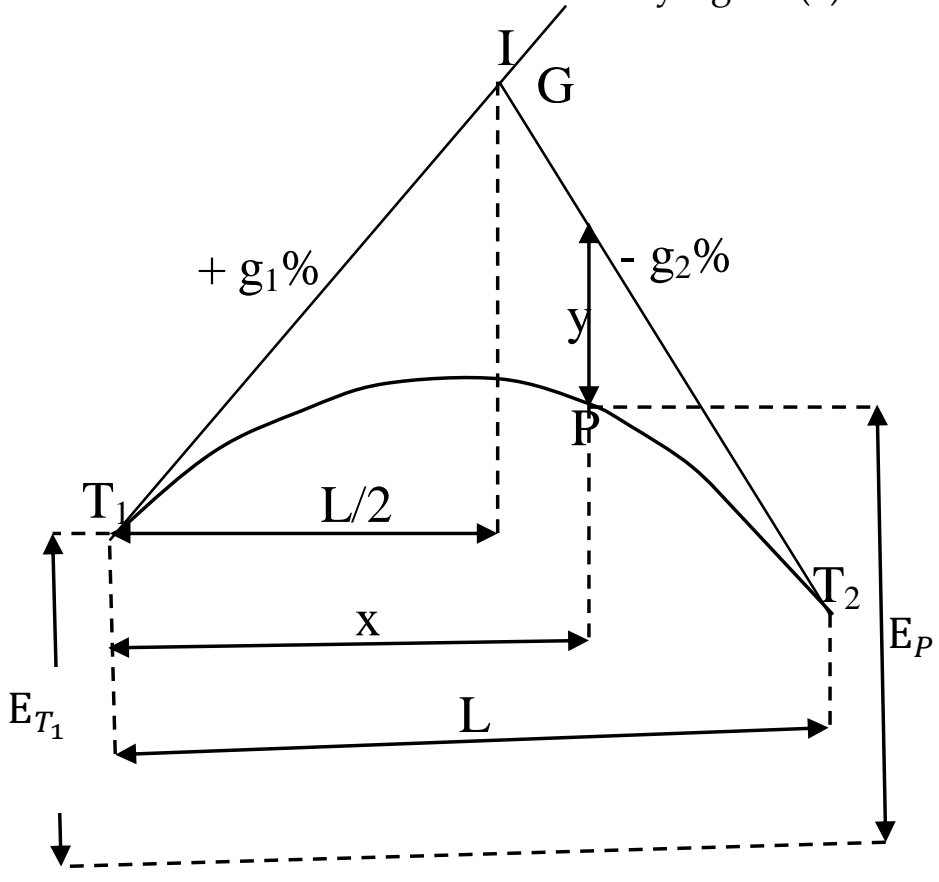

Fig. 1. Elements of the vertical curve 
Where $g_{1}$ is the first gradient, $g_{2}$ is the second gradient, I is vertical intersection point, $\mathrm{L}$ is the length of the vertical curve, $\mathrm{T}_{1}$ is the beginning of the vertical curve, $T_{2}$ is the end of the vertical curve. $\mathrm{Y}$ is the ordinate at any point $\mathrm{p}$ at a distance $x$ from $T_{1}, E_{11}$ is the elevation of $T_{1}$, and Ep is the elevation of point $\mathrm{p}$.

\section{THE GENERAL EQUATION OF THE VERTICAL} PARABOLIC CURVE

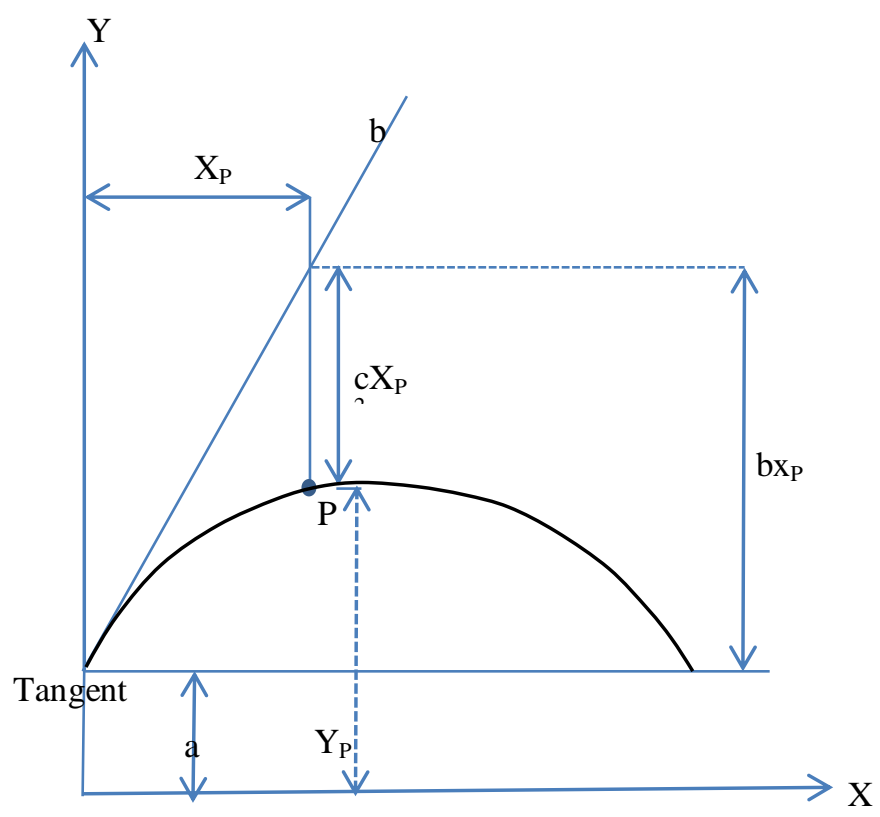

Fig. 2. General Relations of the Vertical Curve

Referring to Fig. 2, the general mathematical expression of a parabola, with to an $\mathrm{X} \mathrm{Y}$ rectangular coordinate system, is given by:

$$
Y_{p}=a+b X_{p}+c X_{p}^{2}
$$

Where $Y_{p}$ is the ordinate at any point $p$ on the parabola at a distance $X_{p}$ and $a, b$, and $c$ are constants.

In surveying terminology, the equation of an equal tangent vertical parabolic curve is given by the following equation:

Where:

$$
E=E_{B V C}+g_{1} X+c X^{2}
$$

Eвvс $=\mathrm{a}$, and $c=\left(\frac{\mathrm{g}_{2}-\mathrm{g}_{1}}{2 L}\right)$

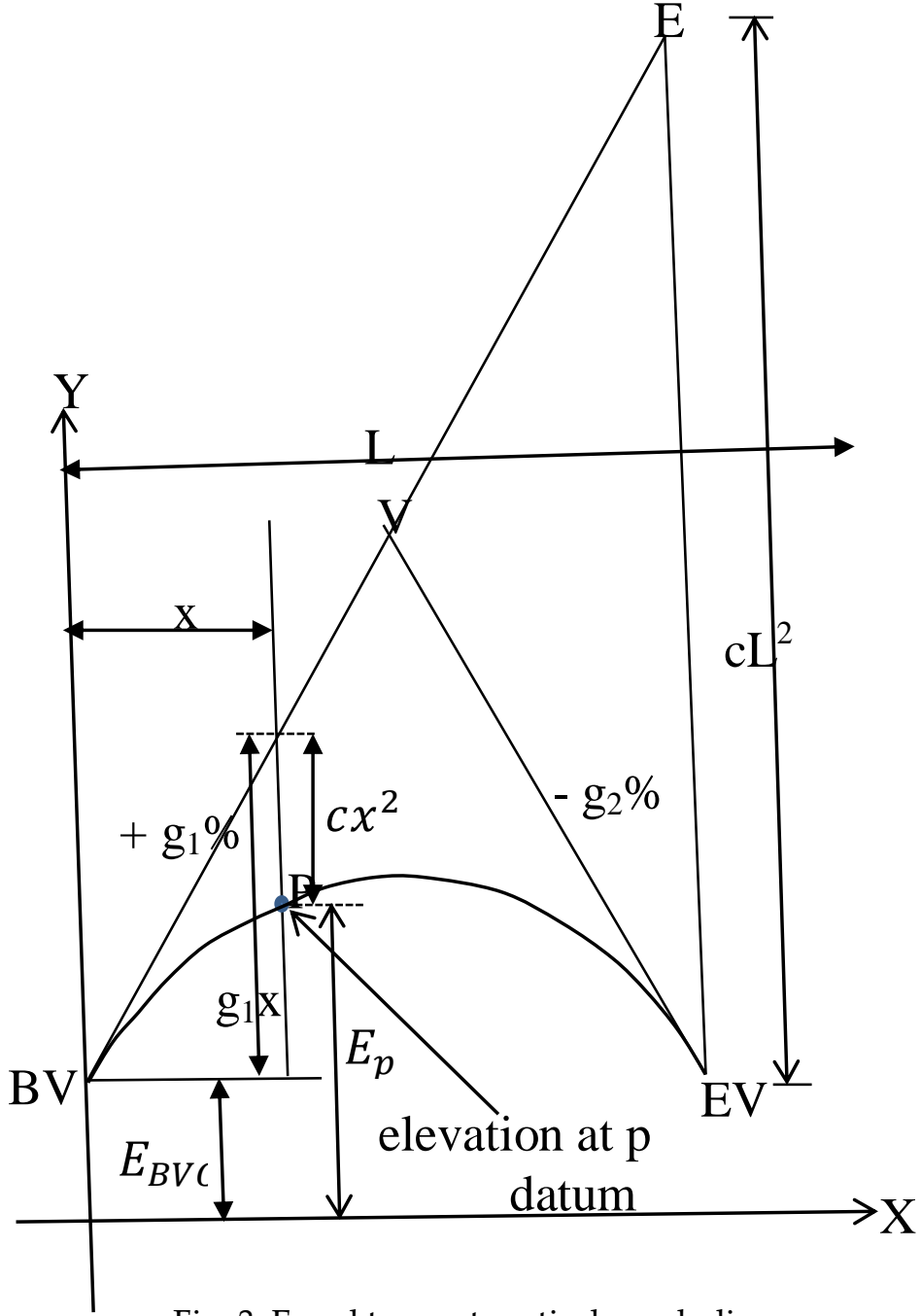

Fig. 3. Equal tangent vertical parabolic curve

Elevations on the center of the vertical curve can be determined by the following equation:

$$
E_{P_{i}}=E_{B V C}+\frac{\mathrm{g}_{1}}{100} x_{i}+\frac{\left(\mathrm{g}_{2}-\mathrm{g}_{1}\right)}{200 L} x_{i}^{2}
$$

Where $p_{i}$ represents any point on the vertical curve, $x_{i}$ is the distance of the point from beginning of the curve, $E_{p i}=e l e v a t i o n$ of point $p_{i}$, Eвvс $=$ elevation of point of beginning of the curve [4].

An unequal tangent vertical curve is simply treated as a pair of equal tangent curves, where the end of the first curve is the beginning of the second curve 


\section{A DeVeloped Vertical Parabolic Curve CALCULATOR}

In this study an electronic program for vertical curve computations was developed in form of electronic calculator, and the algorithm is implemented in Microsoft Windows C++. To employ the algorithm the user must enter the required parameters from a graphical user interface [3]. These parameters are namely, the curve length, backward tangent grade, forward tangent grade, setting out interval, and the elevation of the intersection point. Fig. (4) shows the required parameters to be entered.

As an example let us consider the following case: a falling grade of $-2.54 \%$ intersects a rising grade of $+1.07 \%$ at a vertex whose elevation is $376.492 \mathrm{~m}$. If it is required to join the two tangents by an equal tangent parabolic curve of $180 \mathrm{~m}$ length, at $20 \mathrm{~m}$ interval.

Solution: using the traditional method:

$E_{P_{i}}=E_{B V C}+\frac{\mathrm{g}_{1}}{100} x_{i}+\frac{\left(\mathrm{g}_{2}-\mathrm{g}_{1}\right)}{200 L} x_{i}^{2}$

$E_{B V C}=$ Station $0=E_{V}-\left(\frac{\mathrm{g}_{1}}{100} * \frac{L}{2}\right)=376.492-$ $\left(\frac{-2.54}{100} * \frac{180}{2}\right)=378.778 m$

$\mathrm{g}_{2}-\mathrm{g}_{1}=1.07+2.54=3.61$

$\mathrm{E}_{\mathrm{P}_{1}}=378.778+\left(\frac{-2.54}{100}\right) \times 20+\left(\frac{3.61}{200 \times 180}\right)(20)^{2}=$ $378.310 m$

$\mathrm{E}_{\mathrm{P}_{2}}=378.778+\left(\frac{-2.54}{100}\right) \times 40+\left(\frac{3.61}{200 \times 180}\right)(40)^{2}=$ $377.922 m$

$\mathrm{E}_{\mathrm{P}_{3}}=378.778+\left(\frac{-2.54}{100}\right) \times 60+\left(\frac{3.61}{200 \times 180}\right)(60)^{2}=$ $377.615 m$

$\mathrm{E}_{\mathrm{P}_{4}}=378.778+\left(\frac{-2.54}{100}\right) \times 80+\left(\frac{3.61}{200 \times 180}\right)(80)^{2}=$ $377.388 m$

$$
\begin{aligned}
\mathrm{E}_{\mathrm{P}_{5}}=378.778 & +\left(\frac{-2.54}{100}\right) \times 100 \\
& +\left(\frac{3.61}{200 \times 180}\right)(100)^{2}=377.241 \mathrm{~m}
\end{aligned}
$$

$\mathrm{E}_{\mathrm{P}_{6}}=378.778+\left(\frac{-2.54}{100}\right) \times 120$

$$
+\left(\frac{3.61}{200 \times 180}\right)(120)^{2}=377.174 m
$$

$$
\begin{aligned}
\mathrm{E}_{\mathrm{P}_{7}}=378.778 & +\left(\frac{-2.54}{100}\right) \times 140 \\
& +\left(\frac{3.61}{200 \times 180}\right)(140)^{2}=377.187 \mathrm{~m}
\end{aligned}
$$

$$
\begin{aligned}
\mathrm{E}_{\mathrm{P}_{8}}=378.778 & +\left(\frac{-2.54}{100}\right) \times 160 \\
& +\left(\frac{3.61}{200 \times 180}\right)(160)^{2}=377.281 \mathrm{~m}
\end{aligned}
$$$$
\mathrm{E}_{\mathrm{P}_{9}}=378.778+\left(\frac{-2.54}{100}\right) \times 180
$$$$
+\left(\frac{3.61}{200 \times 180}\right)(180)^{2}=377.455 m
$$

\begin{tabular}{|l|l|l|l|l|l|l|l|l|l|}
\hline Station & $20 \mathrm{~m}$ & $40 \mathrm{~m}$ & $60 \mathrm{~m}$ & $80 \mathrm{~m}$ & $100 \mathrm{~m}$ & $120 \mathrm{~m}$ & $140 \mathrm{~m}$ & $160 \mathrm{~m}$ & $180 \mathrm{~m}$ \\
\hline
\end{tabular}

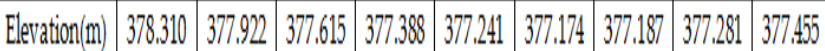

Fig. 4 shows the required parameters to be entered, whereas Fig. 5 shows the results of solution of the same example using the developed program. 


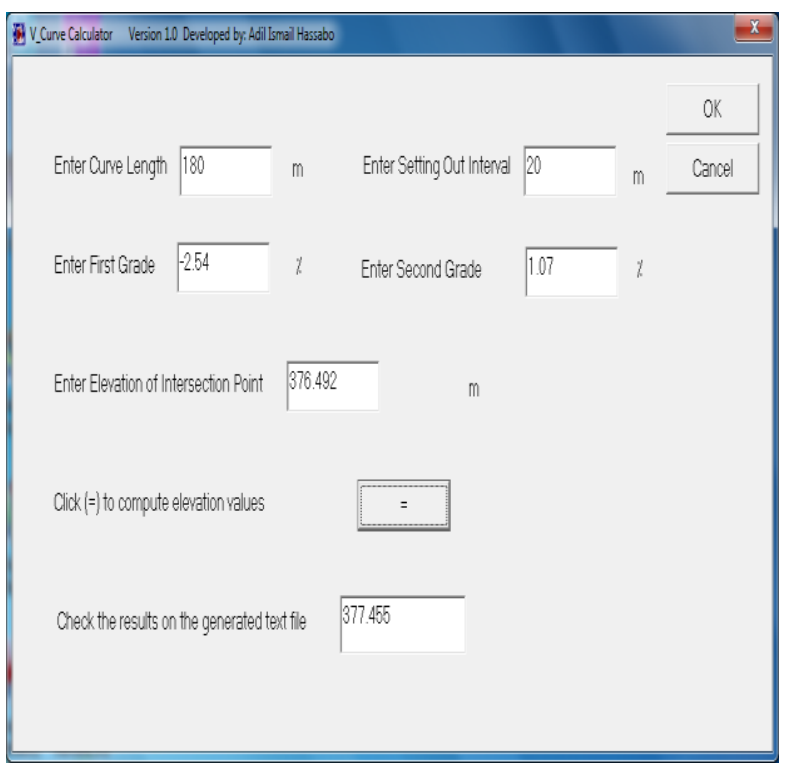

Fig. 4. Parameters to be entered

\section{Elevationsfile2.txt - Notepad}

\section{File É dit Format View Help}

station: 0m: value of elevation is: 378.778

station: 20m: value of elevation is: 378.31

station: 40m: value of elevation is: 377.922

station: $60 \mathrm{~m}$ : value of elevation is: 377.615

station: $80 \mathrm{~m}$ : value of elevation is: 377.388

station: $100 \mathrm{~m}$ : value of elevation is: 377.241

station: $120 \mathrm{~m}$ : value of elevation is: 377.174

station: $140 \mathrm{~m}$ : value of elevation is: 377.187

station: $160 \mathrm{~m}$ : value of elevation is: 377.281

station: $180 \mathrm{~m}$ : value of elevation is: 377.455

Fig. 5. Results shown on a generated text file

\section{CONCLUSIONS}

a. An electronic vertical parabolic curve calculator had been developed in Microsoft Windows.

b. the developed calculator is faster, easier, accurate, and less subject to errors comparable to the traditional method of calculations.

c. The computed results by the developed calculator are written to a text file, so they can be printed and taken to the field for setting out.

\section{REFERENCES}

[1] A. BANNISTER, S. RAYMOND \& R. BAKER, Surveying, Sixth Edition, Long Man Group, UK, 1992

[2] Charles D. Ghilani. Paul R. Wolf, Elementary Surveying An Introduction to Geomatics, Thirteenth Edition, Pearson Education, 2012.

[3] Jon Bates and Tim Tompkins, Practical Visual C++ 6, Eastern Economy Edition, Prentice-Hall of India Private Limited, 1999.

[4] W. SCHOFIELD, Engineering Surveying, Fifth Edition, Replika Press, Delhi, India, 2002. 